\title{
COMPORTAMENTO DO ÁCARO DA LEPROSE DOS CITROS EM DIFERENTES CERCAS-VIVAS E QUEBRA-VENTOS UTILIZADOS EM POMARES CÍTRICOS DA REGIÃO DE BEBEDOURO, SP
}

Luís Fernando Ulian ${ }^{1}$ Carlos Amadeu Leite de Oliveira ${ }^{2}$

\section{RESUMO}

Objetivou-se avaliar a capacidade inata do ácaro Brevipalpus phoenicis de hospedar-se nas principais espécies de cercas-vivas e quebra-ventos. Num primeiro bioensaio, em laboratório, utilizaram-se folhas inteiras das seguintes espécies vegetais: amora (Morus sp), azaléia (Rhododendron indicum), hibisco (Hibiscus sp), jambolão (Eugenia laevigata), napier (Pennisetum purpureum), ponciros (Poncirus trifoliata), primavera (Bougainvillea spectabilis), sansão-do-campo (Mimosa caesalpiniaefolia) e urucum (Bixa orellana), as quais foram colocadas em placas de Petri, sobre uma camada de algodão hidrófilo constantemente umedecida. Estabeleceram-se 5 repetições para cada espécie vegetal. Cada unidade experimental foi constituída de uma folha, para a qual foram transferidas 15 fêmeas. Após a transferência das fêmeas, fizeram-se as avaliações das populações do acarino, a intervalos de 5 dias. Em casa-de-vegetação, foi realizado um outro ensaio, utilizando as espécies: grevílea (Grevillea robusta), hibisco (Hibiscus sp), jambolão ( $E$. laevigata), malvavisco (M. mollis), pínus (Pinus sp), ponciros ( $P$. trifoliata), primavera ( $B$. spectabilis), sansão-do-campo ( $M$. caesalpiniaefolia) e urucum ( $B$. orellana). Cada tratamento era representado por 5 plantas, para as quais foram transferidas 100 fêmeas/planta. Decorridos 60 dias, efetuou-se a avaliação da população de $B$. phoenicis. Os resultados observados através da colonização de mudas de cercas-

1 Fundecitrus, Av. Adhemar P. de Barros, nº 201, 14807-040, Araraquara, SP, Brasil 2 Dep. de Fitossanidade da FCAV/UNESP, Via de Acesso Prof. Paulo Donato Castellane, $\mathrm{s} / \mathrm{n}^{\circ}, 14884-900$, Jaboticabal, SP, Brasil. 
vivas e quebra-ventos com $B$. phoenicis, em casa-de-vegetação, mostraram-se mais confiáveis para a seleção de plantas hospedeiras do que os bioensaios utilizando folhas destacadas, dadas as dificuldades surgidas, de modo que as espécies hibisco (Hibiscus sp) e urucum (B. orellana) devem ser evitadas por proporcionarem condições favoráveis de sobrevivência do $B$. phoenicis e, assim, comportar-se como focos de infestação aos pomares cítricos.

Palavras-chave: citros, Tenuipalpidae, manejo integrado, controle biológico, Brevipalpus phoenicis.

\section{ABSTRACT}

\section{LEPROSIS CITRUS MITE (Brevipalpus phoenicis GEIJSKES, 1939) BEHAVIOR ON DIFFERENT PLANTS SPECIES, USED AS WIND-BREAK IN CITRUS ORCHARDS}

The experiments were carried out to evaluate Brevipalpus phoenicis mite ability to live on citrus orchards wind-breaks. The first one, under laboratory conditions, had entire leaves of several species: Morus sp., Rhododendron indicum, Hibiscus sp., Eugenia laevigata, Pennisetum purpureum, Poncirus trifoliata, Bougainvillea spectabilis, Mimosa caesalpiniaefolia, and Bixa orellana. Five replications were established for each plant species, and the leaves put in Petri plates on cotton, kept constantly wet. Every experimental unity was composed for one leaf, with 15 female mites transferred to it. Evaluations of mite population were done at intervals of five days. The second trial was carried out in a greenhouse, using seeds of several plant species: Grevillea robusta, Hibiscus sp, E. laevigata, $M$. mollis, Pinus sp., P. trifoliata, B. spectabilis, M. caesalpiniaefolia and B. orellana. Each treatment (species) had five replications (plants), receiving 100 female mites of B. phoenicis. After 60 days the leprosis mite population was evaluated. Results showed that the second trial gave more reliable data for selecting host plants. The data showed that Hibiscus sp. and $B$. orellana should not be used as wind-breaks because they provide 
favourable conditions for $B$. phoenicis survival and bring consequently reinfestation on citrus orchards.

Key words: Citrus sinensis, Tenuipalpidae, integrated pest management.

\section{INTRODUÇÃO}

Dentre as várias táticas adotadas num sistema de manejo integrado de pragas (MIP), sobressai o uso de cercas-vivas e quebra-ventos que, além de evitar a entrada de pessoas intrusas e tráfego de maquinários sem a devida desinfecção, também serve para diminuir a velocidade do vento, principal agente disseminador do ácaro Brevipalpus phoenicis (Geijskes, 1939), transmissor da leprose e de outras pragas, além de proteger contra a poeira, que proporciona melhores condições para o desenvolvimento do acarino. Todavia, as cercas-vivas e os quebra-ventos poderão ser uma séria ameaça ao pomar cítrico, pois, considerando apenas o manejo do ácaro, podem comportar-se de três maneiras distintas: como hospedeiras alternativas, como depositária do vírus ou fornecendo nichos adequados à instalação de populações de seus inimigos naturais. A maior ou menor preferência do acarino a uma ou outra espécie vegetal é um quesito muito importante a ser considerado quando da escolha da cerca-viva ou quebra-vento.

O objetivo deste trabalho foi conhecer alguns aspectos da interrelação $B$. phoenicis e cercas-vivas e quebra-ventos, principalmente dos que vêm sendo utilizados nos pomares cítricos da região, bem como nos viveiros de produção de mudas.

\section{MATERIAL E MÉTODOS}

\section{Criação estoque}

A criação estoque foi desenvolvida a partir de laranjas da variedade Pêra-Rio, coletadas em pomares cítricos da região de Bebedouro, SP, que, há vários meses, não haviam sido pulverizados com defensivos e apresentavám sintomas de verrugose, pois o ácaro B. phoenicis tem preferência por frutos com superfície irregular (Albuquerque et al., 1995). 
Os frutos foram levados para o laboratório de Acarologia da FCAVJ/UNESP, onde, para sua melhor conservação, foram parcialmente parafinados, deixando-se uma área circular, para a qual se transferiram ácaros B. phoenicis. A área não parafinada foi delimitada por uma barreira adesiva tanglefoot, para impedir a fuga dos acarinos. Os frutos foram dispostos sobre bandejas plásticas, semelhantes às usadas para o transporte de ovos de galinha.

Os ácaros transferidos foram obtidos de laranjas de pomares mantidos em condições semelhantes aos que forneceram os frutos para o início da criação. A transferência dos ácaros realizou-se com o auxílio de pincel com poucos pêlos e com a colocação dos frutos preparados sobre placas de vidro, onde estavam os ácaros obtidos por máquina de varredura.

Aproximadamente a cada 2 meses, a criação foi revigorada com ácaros da mesma procedência.

No decorrer do experimento, os frutos em início de deterioração eram substituídos, e a transferência dos ácaros efetuada pela sua justaposição a frutos sadios.

A criação foi mantida em câmara climatizada à temperatura de $25 \pm 1^{\circ} \mathrm{C}$, umidade relativa de $60 \pm 5 \%$ e fotofase de 14 horas.

\section{Comportamento de B. phoenicis sobre folhas destacadas e mudas de plantas utilizadas como cercas-vivas e quebra-ventos}

Objetivando selecionar plantas (cercas-vivas e quebra-ventos) menos favoráveis ao desenvolvimento de $B$. phoenicis, optou-se inicialmente pela utilização de partes vegetais como substrato para a verificação da sobrevivência e desenvolvimento populacional dos acarinos. Para tanto, utilizaram-se folhas inteiras das seguintes espécies vegetais: amora (Morus sp), azaléia (Rhododendron indicum), hibisco (Hibiscus sp), jambolão (Eugenia laevigata), napier (Pennisetum purpureum), ponciros (Poncirus trifoliata), primavera (Bougainvillea spectabilis), sansão-docampo (Mimosa caesalpiniaefolia) e urucum (Bixa orellana), colocadas em placas de Petri, sobre uma camada de algodão hidrófilo mantida constantemente umedecida. 
Dado o comportamento do acarino em localizar-se preferencialmente na superfície abaxial das folhas das plantas que o hospedam, as folhas utilizadas no estudo foram colocadas com sua parte abaxial voltada para eima. Para impedir a fuga dos ácaros das folhas, empregou-se tanglefoot nas suas bordas.

Estabeleceram-se 5 repetições para cada espécie vegetal. Cada unidade experimental foi constituída de uma folha, para a qual foram transferidas 15 fêmeas.

Para favorecer a oviposição e diminuir a fuga dos ácaros, foi colocado gesso em pó sobre a superfície das folhas.

As placas de Petri, com as diferentes espécies vegetais, foram mantidas em câmara climatizada à temperatura de $25 \pm 1^{\circ} \mathrm{C}$, umidade relativa de $60 \pm 5 \%$ e fotofase de 14 horas (Trindade \& Chiavegato, 1994).

Após a transferência das fêmeas, fizeram-se as avaliações das populações dos acarinos, a intervalos de 5 dias.

As maiores dificuldades surgidas no desenvolvimento da pesquisa restringiram-se basicamente à durabilidade das folhas utilizadas para o desenvolvimento dos acarinos, pois, na maioria, secaram ou apodreceram antes do tempo necessário para que o ácaro completasse o ciclo. Em razão disso, os parâmetros biológicos foram avaliados somente até o $10^{\underline{0}}$ dia após a transferência das fêmeas.

\section{Capacidade de colonização de $B$. phoenicis em diferentes mudas de cercas-vivas e quebra-ventos}

Os bioensaios de colonização de B. phoenicis, em mudas de grevílea (G. robusta), hibisco (Hibiscus sp), jambolão (E. laevigata), malvavisco (M. mollis), pínus (Pinus sp), ponciros (P. trifoliata), primavera (B. spectabilis), sansão-do-campo (M. caesalpiniaefolia) e urucum (B. orellana), foram conduzidos em casa-de-vegetação.

As mudas de cercas-vivas e quebra-ventos foram formadas no Horto Florestal da FCAVJ/UNESP, com as práticas culturais normalmente adotadas. Foram cultivadas em vasos, com partes iguais de terra, areia e esterco de curral curtido, e irrigação, quando necessário.

As plantas foram previamente lavadas e desinfestadas de possí- 
veis insetos ou ácaros, com pincel e algodão umedecido. Na base dos caules das mudas, rente à superfície do solo, foi feita uma barreira com tanglefoot, com o objetivo de impedir a fuga ou a entrada de predadores (Trindade \& Chiavegato, 1994). A metodologia baseou-se na transferência de 500 fêmeas de $B$. phoenicis em cinco mudas ( 100 fêmeas por muda) de cada espécie.

As mudas foram mantidas em casa-de-vegetação, registrando-se as variações nas condições meteorológicas, com temperatura média de $25,6^{\circ} \mathrm{C}$ e a umidade relativa de $66,1 \%$, na primeira etapa, e $22,85^{\circ} \mathrm{C}$ e $80,91 \%$, respectivamente, na segunda.

Decorridos 60 dias da transferência dos ácaros, tempo suficiente para que, em condições normais, se completassem dois ciclos vitais, foi realizada a avaliação da população do $B$. phoenicis. Todas as plantas tiveram suas folhas destacadas e os ramos repicados para serem submetidos a uma máquina de varredura, modelo Jaboticabal (Oliveira, 1983), para a retirada dos ácaros e contagem das formas jovens e adultas, utilizando-se, para tanto, microscópio estereoscópico. A adoção deste método somente não foi empregada para o pínus (Pinus sp.), dada a sua morfologia foliar e possível permanência do ácaro junto à base das acículas, adotando-se neste caso a extração de ácaros com o uso de água mais detergente. Os ramos e folhas foram submersos em cubas, com essa mistura sob constante agitação, por 10 minutos, findos os quais foram retirados e a calda filtrada. Decorridos alguns minutos, até a secagem parcial do papel filtro, com auxílio de microscópio estereoscópico, anotou-se o número de ácaros retidos no papel.

A colonização de $B$. phoenicis em pínus (Pinus sp.) foi repetida numa segunda etapa, com o intuito de confirmar os dados obtidos.

\section{Análise estatística dos dados}

Os dados observados foram transformados em $\mathrm{L}(\mathrm{x}+5)(\mathrm{L}=$ logaritmo natural) para serem submetidos a análise da variância, e as médias comparadas pelo teste de Tukey a $5 \%$ de probabilidade. 


\section{RESULTADOS E DISCUSSÃO}

\section{Comportamento de B. phoenicis sobre folhas destacadas e mudas de plantas utilizadas como cercas-vivas e quebra-ventos}

Os parâmetros biológicos do B. phoenicis avaliados nas diferentes espécies de cercas-vivas e quebra-ventos encontram-se nas Tabelas 1 e 2.

Analisando-se a Tabela 1, nota-se que as espécies de cercas-vivas e quebra-ventos que mais favoreceram a oviposição, de maneira decrescente, em relação ao número de ovos, foram: ponciros (160;270), hibisco $(128 ; 217)$, amora $(76 ; 213)$, jambolão $(73 ; 48)$, sansão-do-campo $(52$; $51)$, azaléia $(R$. indicum $)(25 ; 52)$, primavera $(15 ; 19)$, urucum $(2 ; 3)$ e napier $(2 ; 1)$.

Quanto ao número de larvas, constata-se que o hibisco sobressai frente às outras espécies, com 28 larvas no $10^{\circ}$ dia, seguido da amora, com duas larvas no $5^{\circ}$ dia e 9 larvas no $10^{\circ}$. As espécies primavera, jambolão, ponciros, sansão-do-campo e urucum tiveram $3,2,1,1$ e 1 larvas emergidas, respectivamente, avaliadas no $10^{\circ}$ dia. Nas espécies azaléia e napier não foram constatadas larvas.

Com base na Tabela 1, calcularam-se dados referentes às porcentagens de fêmeas retidas na barreira adesiva (fuga), mortalidade e sobrevivência de $B$. phoenicis, a partir de 75 fêmeas transferidas para cada espécie vegetal. Com relação à fuga, o sansão-do-campo apresentou o maior percentual, bem superior aos demais; quanto à mortalidade, sobressaíram as espécies urucum, primavera $\epsilon$ napier, com 60, 60 e 54,67\%, avaliados 10 dias após. Em contrapartid ́x, hibisco (78,67\%), azaléia (72\%), amora $(70,67 \%)$, jambolão $(68 \%)$ e ponciros $(66,66 \%)$, avaliados no $10^{\circ}$ dia, foram os que proporcionaram maior sobrevivência, enquanto que $o$ sansão-do-campo apresentou a menor sobrevivência e a maior fuga.

A Tabela 2 mostra as médias referentes à avaliação feita no $10^{\circ}$ dia, confirmando os dados apresentados na Tabela 1. Esta análise comprova que as espécies que mais favoreceram a oviposição foram o ponciros, o hibisco e a amora, sendo as duas primeiras já citadas como hospedeiras por Paschoal (1969) e Trindade \& Chiavegato (1994), respectivamente. 
Tabela 1. Números de ovos e larvas de Brevipalpus phoenicis avaliados 5 e 10 dias após a transferência das fêmeas para folhas destacadas de diferentes espécies de cercas-vivas e quebraventos. Jaboticabal, SP.

\begin{tabular}{lrrr}
\hline Espécie vegetal & Dias após a transferência & Ovos & Larvas \\
\hline Amora & 5 & 76 & 2 \\
(Morus sp) & 10 & 213 & 9 \\
\hline Azaléia & 5 & 25 & - \\
(Rhododendron indicum) & 10 & 52 & - \\
\hline Hibisco & 5 & 128 & - \\
(Hibiscus sp) & 10 & 217 & 28 \\
\hline Jambolão & 5 & 73 & - \\
(Eugenia laevigata) & 10 & 48 & 2 \\
\hline Napier & 5 & 2 & - \\
(Pennisetum purpureum) & 10 & 1 & - \\
\hline Ponciros & 5 & 160 & - \\
(Poncirus trifoliata) & 10 & 270 & 1 \\
\hline Primavera & 5 & 15 & - \\
(Bougainvillea spectabilis) & 10 & 19 & 3 \\
\hline Sansão-do-campo & 5 & 52 & - \\
(Mimosa caesalpiniaefolia) & 10 & 51 & 1 \\
\hline Urucum & 5 & 2 & - \\
(Bixa orellana) & 10 & 3 & 1 \\
\hline
\end{tabular}

Tabela 2. Médias dos números de ovos e larvas de Brevipalpus phoenicis avaliados 10 dias após a transferência das fêmeas para folhas destacadas de diferentes espécies de cercas-vivas e quebra-ventos. Jaboticabal, SP.

\begin{tabular}{|c|c|c|}
\hline Espécie vegetal & Ovos* & Larvas* \\
\hline Amora (Moins sp) & $3.7126 \mathrm{a}$ & $1,8980 \quad b$ \\
\hline Azaléia (Rhododendro: indicum) & $2,7227 \quad b$ & $1.6094 \quad b$ \\
\hline Hibisco (Hibiscus sp) & $3.8714 \mathrm{a}$ & $2,2933 \mathrm{a}$ \\
\hline Jambolão (Eugenia laevigata) & $2,6585 \quad b$ & $1,6824 \mathrm{~b}$ \\
\hline Napier (Pennisetun purpureum) & $1.6459 \mathrm{c}$ & $1,6094 \quad b$ \\
\hline Ponciros (Poncirus trifoliata) & $4,0574 \mathrm{a}$ & $1,6459 \mathrm{~b}$ \\
\hline Primavera (Bougainvillea spectabilis) & $2.1024 b c$ & $1.7132 \quad b$ \\
\hline Sansão-do-campo (Mimosa caesalpiniaefolia) & $2.6549 \mathrm{~b}$ & $1.6459 \quad \mathrm{~b}$ \\
\hline Urucum (Bixa orellana) & $1.7132 \mathrm{c}$ & $1.6459 \mathrm{~b}$ \\
\hline F(Tratamento) & $35.83 * *$ & $7,64 * *$ \\
\hline Coeficiente de Variação (CV) & 12,15 & 10,28 \\
\hline$\Delta$ (Tukey) & 0,7136 & 0,3779 \\
\hline
\end{tabular}

*médias acompanhadas de mesma letra, na coluna, não diferem estatisticamente entre si ao nível de $5 \%$ de probabilidade. 


\section{Capacidade de colonização do B. phoenicis em diferentes mudas de cercas-vivas e quebra-ventos}

Os dados relativos à avaliação da capacidade de colonização do $B$. phoenicis obtidos após 60 dias da transferência dos ácaros para as diferentes mudas de cercas-vivas e quebra-ventos acham-se reunidos na Tabela 3.

Observou-se que, dentre as espécies estudadas, as menos favoráveis ao desenvolvimento do $B$. phoenicis foram: pínus (Pinus sp), primavera ( $B$. spectabilis), sansão-do-campo ( $M$. caesalpiniaefolia) e jambolão (E. laevigata). As espécies ponciros ( $P$. trifoliata), grevílea ( $G$. robusta) e malvavisco (M. mollis) podem ser consideradas como intermediárias à capacidade de colonização do acarino, pela análise estatística, e hibisco (Hibiscus sp) e urucum (B. orellana) como as mais favoráveis.

Os resultados conseguidos através da colonização de mudas de cercas-vivas e quebra-ventos com $B$. phoenicis mostraram-se mais confiáveis para a seleção de plantas hospedeiras do que os bioensaios com folhas destacadas, dada a série de dificuldades surgidas. O urucum, que, no método das folhas destacadas apresentou baixo número de ovos, no método de colonização de mudas, mostrou-se dentre as mudas a mais favorável ao acarino. Há que considerar, também, que o acarino procura locais protegidos para efetuar a postura, o que nem sempre ocorre nas folhas dealgumas espécies vegetais.

Tabela 3. Brevipalpus phoenicis avaliado 60 dias após a transferência de 100 ácaros adultos/planta para as espécies de cercas-vivas e quebra-ventos. Jaboticabal, SP.

\begin{tabular}{|l|r|r|}
\hline Planta & Total & Média* \\
\hline Urucum & 744 & $4,4916 \mathrm{a}$ \\
Hibisco & 472 & $4,4806 \mathrm{a}$ \\
Malvavisco & 227 & $3,7959 \mathrm{ab}$ \\
Grevíea & 207 & $3,5529 \mathrm{abc}$ \\
Ponciros & 131 & $3,2403 \mathrm{abcd}$ \\
Jambolão & 67 & 2,7962 bcde \\
Sansāo-do-campo & 41 & 2,5314 bcde \\
Primavera & 35 & 2,3284 cde \\
Pínus-2 ensaio $_{\text {Pínus-1 }}^{\underline{Q} \text { ensaio }}$ & 20 & 2,0868 de \\
\hline
\end{tabular}

*médias acompanhadas de mesma letra não diferem estatisticamente entre si. 


\section{AGRADECIMENTO}

À FAPESP, pela concessão da Bolsa e Auxílio à Pesquisa.

\section{REFERÊNCIAS BIBLIOGRÁFICAS}

ALBUQUERQUE, F.A.; C.A.L.; OLIVEIRA \& M. BARRETO, 1995.

Comportamento do Ácaro Brevipalpus phoenicis (Geijskes, 1939) (Acari: Tenuipalpidae) em Frutos de Citros. In: OLIVEIRA, C.A.L. \& L.C. DONADIO (eds) Leprose dos Citros. Jaboticabal, FUNEP, p.77-90. OLIVEIRA, C.A.L. 1983. Máquina de Varredura de Ácaros "Modelo Jaboticabal". Anais da Sociedade Entomológica do Brasil, 12(2):299-303.

PASCHOAL, A.D, 1969. Ácaros Encontrados em Plantas no Estado de São Paulo. Revista de Agricultura, 54(2-3):76-78.

TRINDADE, M.L.D. \& L.G. CHIAVEGATO, 1994. Caracterização Biológica dos Ácaros Brevipalpus obovatus D., B.californicus B. e B.phoenicis G. (Acari: Tenuipalpidae). Anais da Sociedade Entomológica do Brasil, 23(2):189-195. 